AARP INTERNATIONAL THE JOURNAL

VOLUME $11-2018$ EDITION

AAPP

Real Possibilities

\title{
Looking East: A Rising Sun on Innovations to Support Later Life
}

By Brian Beach 


\title{
Looking East: A Rising Sun on Innovations to Support Later Life
}

\author{
By Brian Beach
}

W

hile many may associate Japan with more stereotypically 'youthful' trends like new technology, video games, or anime, those of us working in the field of population aging have long recognized the country's importance as it faces the reality of shifting demographics. We often discuss the value in looking at Japan for innovative solutions to some of the challenges arising from an aging population, given how being somewhat 'ahead of the curve' in this respect has compelled it to explore such opportunities.

In May 2017, colleagues and I from the International Longevity Centre - UK (ILC-UK) took advantage of the link with our sister organization, ILCJapan, to conduct a study mission on aging in Japan. Through the financial support of the Daiwa Anglo-Japanese Foundation and the Great Britain Sasakawa Foundation, we explored Japanese approaches to tackle the challenges of demographic change and take advantage of the opportunities afforded by longer lives. The study trip included seven site visits in three areas in and around Tokyo, two of which were local government offices that have taken important steps to promote activity in support of older people.

Before embarking on our site visits, our trip began with a knowledge exchange session, with each ILC team describing the approaches to long-term care in our respective countries. ILCJapan also gave an overview of aging trends in Japan for context. By 2025, population aging in Japan will become an urban phenomenon rather than a rural one, due to historical internal migration to cities. Also - in contrast to an often- heard assumption that Asian societies feature high levels of social solidarity and engagement - we heard that social connections are becoming weaker as the baby boomer generation and urban residents tend to hold great value in their privacy and independence. Alongside cuts to services from local and national governments in recent years, this has placed greater responsibility for care onto families and communities, who are already experiencing exhaustion from the pressures; in some areas, aging has led to a situation where only one person is in the position to look after an entire community.

\section{New Realities, New Ideas}

In response to these sometimes stark realities, concerted efforts have investigated new ideas and programs along four main themes:

- Creating a change in mindset: With a shift from mutual help to loose ties, some approaches have looked to encourage 'self-help', while also recognizing that helping others can itself have personal benefits.

- Getting people involved before they need help: Preventive action and early identification of issues generate better outcomes across a range of health and well-being outcomes; engaging people through examples like community centers can also combat isolation.

- New partnerships between local government and local organizations: Organizations rely on logistic support from municipalities, but they remain independent and work collaboratively rather than operating as subcontractors for government services.

- Creating places for everyone to play a role: Important in the context of dementia, some programs are designed to engage participants in the greatest extent possible, e.g. by organizing small work opportunities in the community as a group.

In Japan, there is a strong emphasis on the notion of productive aging, fostered through integration and development of community links. Indeed, long-term care reforms in the past decade have promoted the establishment of the Integrated Community-based Care approach, where medical facilities, nursing care, and social activity groups can all be accessed within 30 minutes from one's residence. Such an approach has two main objectives: to enhance coordination between medical and long-term care services and to promote active and healthy living through social participation, including the necessary support services to achieve this, e.g. for those who have minor issues that impact their ability to go out safely.

\section{Government and Local Organization Partnership: Genki Stations in Yokohama}

Our site visits in Yokohama, south of Tokyo, illustrate some of the points above related to prevention, government engagement, and community-based approaches. We visited a Genki-zukuri Station, a unique program supported by the Yokohama city government. Genki-zukuri translates to something like 


\section{"By 2025, population aging in Japan will become an urban phenomenon rather than a rural one, due to historical internal migration to cities."}

'health generation', and these stations play significant roles in promoting health and various activities to mitigate against the development of care needs across the 18 wards of Yokohama. The activities vary but include exercise classes and workshops on preventing dementia. When we visited, there were 253 active groups across the city, but the aspiration is to develop stations close enough for all older people to reach by walking: in other words, over 350.

Genki Stations are run independently by neighborhood groups with support from the ward office. Indeed, constraints on resources mean it is necessary for such activities to be led by older people themselves. The ward office provides intensive support for around three months to help prepare the activity and get it started. An important element of this is involvement by the district nurse in the ward office, whose role focuses on promoting public health in general. The ward does not offer cash support but does provide various supplies in kind along with covering some other costs associated with startup.

In addition to improving health, an important goal of Genki Stations is to develop social capital. Genki Stations are required to submit data on participation twice a year and conduct annual surveys among participants to examine their effectiveness (and evaluations are a crucial part of any intervention). An ILC-Japan colleague presented analysis from two surveys at one station covering the period 2013-2015. The results support the idea that the station had a positive effect on health and participation in community activities, as well as access to and understanding of new health information. However, there was no impact on social capital (as measured by general trust). This may reflect some of the underlying challenges for Genki Stations in terms of recruiting new members and countering decreasing membership rates.

\section{A Final Reflection}

Our fact-finding mission offered many more lessons and examples than can adequately be described here, but the Genki Station demonstrates how coordinated effort and support from government can address some of the concerns around an aging population, even when there is substantial pressure on public budgets. Providing essential support to get projects like Genki Stations off the ground can be instrumental for their establishment, but ongoing involvement - not necessarily financial - is vital for the continuation of such projects.

While cultural and institutional differences moderate the direct transfer of certain programs to countries like the UK, the examples from Japan should encourage us all to consider how new thinking, innovative strategies, and engagement with older people themselves - as actors, not just beneficiaries - can help our societies flourish as we adapt to the realities of aging in the 21 st century.

A full report on ILC-UK's trip to Japan, as well as similar trip by ILCJapan to London, will be available in 2018 at www.ilcuk.org.uk.

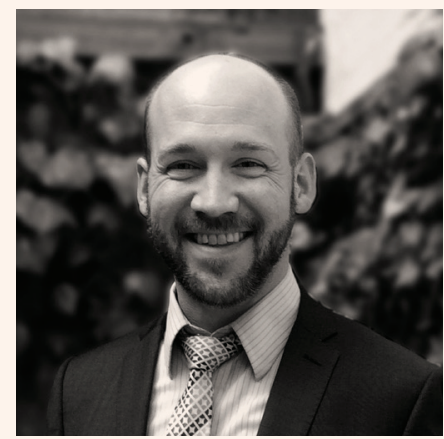

Brian Beach SENIOR RESEARCH FELLOW ILC-UK 
AARP International engages global stakeholders to spark solutions that strengthen communities, protect the vulnerable and enable people around the world to pursue their goals and dreams. Working with governments, civil society and the private sector, we are focused on enhancing the quality of life for people as they age. We serve as the global voice for AARP, a social change organization with a membership of more than 37 million.

THE JOURNAL ONLINE

aarpinternational.org/journal

AARP INTERNATIONAL ONLINE

aarpinternational.org

FACEBOOK

facebook.com/aarpintl

TWITTER

@aarpintl

CONTACT

AARP International

601 E Street, NW

Washington, DC 20049

United States

T +1 2024342398

E international@aarp.org

AARP International: The Journal is a publication of AARP. The views expressed herein do not necessarily represent policies of AARP and should not be construed as endorsements. The mention of a product or service herein is solely for information to our readers and may not be used for any commercial purpose. AARP, which was established in 1958, is a nonprofit, nonpartisan organization with tens of millions of members ages 50 and older. State offices are located in all 50 states, the District of Columbia, Puerto Rico, and the Virgin Islands.

January 2018

()2018, AARP

Reprinting with permission only. 